\title{
Interventional tools to improve medication adherence: review of literature
}

REVIEW

\author{
This article was published in the following Dove Press journal: \\ Patient Preference and Adherence \\ 14 September 2015 \\ Number of times this article has been viewed
}

\begin{abstract}
Elísio Costa'
Anna Giardini ${ }^{2}$

Magda Savin ${ }^{3}$

Enrica Menditto ${ }^{4}$

Elaine Lehane ${ }^{5}$

Olga Laosa ${ }^{6}$

Sergio Pecorelli, 7,8

Alessandro Monaco ${ }^{7}$

Alessandra Marengoni ${ }^{9}$

On behalf of the Al Action

group "Prescription and

Adherence to Medical

Plans", European Innovation

Partnership on Active and

Healthy Ageing

'UCIBIO, REQUIMTE, Faculty of

Pharmacy, University of Porto, Porto,

Portugal; ${ }^{2}$ Psychology Unit, Salvatore

Maugeri Foundation, IRCCS, Scientific

Institute of Montescano (PV), Pavia,

Italy; ${ }^{3}$ European Association of

Pharmaceutical Full-line Wholesalers,

Brussels, Belgium; ${ }^{4} \mathrm{CIRFF} /$ Center

of Pharmacoeconomics, School

of Pharmacy, University of Naples

Federicoll, Nápoles, Italy; ${ }^{5}$ Catherine

McAuley School of Nursing and

Midwifery, Brookfield Health Sciences

Complex, University College Cork,

Cork, Ireland; ${ }^{6}$ Centro de Investigación

Clínica del Anciano Fundación para

la Investigación Biomédica, Hospital

Universitario de Getafe, Madrid, Spain;

${ }^{7}$ Italian Medicines Agency - AIFA,

Rome, Italy; ${ }^{8}$ University of Brescia,

Brescia, Italy; ${ }^{\circ}$ Department of Clinical

and Experimental Science, University

of Brescia, Brescia, Italy
\end{abstract}

Correspondence: Elísio Costa

Department of Biological Sciences,

Faculty of Pharmacy, University of Porto,

Rua de Jorge Viterbo Ferreira, 228,

4050-3 I3 Porto, Portugal

Email emcosta@ff.up.pt

\begin{abstract}
Medication adherence and persistence is recognized as a worldwide public health problem, particularly important in the management of chronic diseases. Nonadherence to medical plans affects every level of the population, but particularly older adults due to the high number of coexisting diseases they are affected by and the consequent polypharmacy. Chronic disease management requires a continuous psychological adaptation and behavioral reorganization. In literature, many interventions to improve medication adherence have been described for different clinical conditions, however, most interventions seem to fail in their aims. Moreover, most interventions associated with adherence improvements are not associated with improvements in other outcomes. Indeed, in the last decades, the degree of nonadherence remained unchanged. In this work, we review the most frequent interventions employed to increase the degree of medication adherence, the measured outcomes, and the improvements achieved, as well as the main limitations of the available studies on adherence, with a particular focus on older persons.
\end{abstract}

Keywords: cognitive impairment, nonadherence, tools, compliance, chronic diseases, elderly

\section{Introduction}

During the last few decades, many different definitions of the process underlying the nonobservance of physician's recommendations have been employed. In the past few years, the concept of adherence has gained popularity as it implies a more mutual and dynamic interaction between patients and health care providers, and it recognizes the influence of medication-taking behavior. ${ }^{1,2}$ Nowadays, the World Health Organization (WHO) definition of adherence has been universally accepted;

$$
\begin{aligned}
& \text {... the extent to which a person's behavior - taking medication, following a diet, and or } \\
& \text { executing lifestyle changes - corresponds with the agreed recommendations from a } \\
& \text { provider. }
\end{aligned}
$$

This definition highlights the importance of an active involvement of the patient with the health professionals with a good communication. ${ }^{3-5}$

The first study on adherence was published in 1968. ${ }^{6,7}$ Later on, several papers have been published on this topic, with the aim to develop measures of adherence, to better understand factors related to poor adherence, and to promote interventions to increase adherence. However, every effort to improve adherence was almost ineffective, and nonadherence to medicines continues to be a challenge for health care professionals and researches. In developed countries, nonadherence to the treatment of chronic diseases ranges from $30 \%$ to $50 \%$, and this rate is even higher in developing countries..$^{8-10}$ This degree of nonadherence results in a higher number of patients whom 
do not achieved the benefits from the prescribed treatment; as a consequence, they experience a poor quality of life and poor health outcomes, and on the other hand, the health care costs increase. ${ }^{11,12}$ Indeed, the improvement of adherence strongly influences health outcomes, when compared to the development of new drugs. ${ }^{4}$

Nonadherence is a challenge in all diseases; it is independent of the type of drug and whether the therapy is chronic or acute. Nonadherence is a multifaceted concept; the focus may be not only on taking drugs but also on timing and not only on discontinuation but also on persistence. Nonadherence is related not only to individual's behavioral factors, but also to the disease itself, complexity and duration of the treatment, possible adverse drug reactions, cost of treatment, and social factors. Moreover, adherence is also affected by patient-provider relationship and/or systemic and organizational factors associated with the health care system. ${ }^{12-15}$ According to the $\mathrm{WHO}$, these determinants of nonadherence can be aggregated into five dimensions: ${ }^{3}$ social and economical, health system related, therapy related, condition related, and patient related (Table 1).

Nonadherence to medical plans is a public health problem at every level of the population, especially in older adults. Multiple chronic diseases and polypharmacy, the coprescription of several drugs, are highly prevalent in older persons. ${ }^{16-18}$ There is evidence that nonadherence

Table I Some examples of the determinants of nonadherence to medical plans aggregated into five dimensions according to World Health Organization

\begin{tabular}{l} 
Social and economic \\
Socioeconomic variables \\
Cost of treatment \\
Health system related \\
Characteristics of the health care provision \\
Patient and prescriber interaction \\
Prescribers follow-up \\
Multiple providers \\
Condition related \\
Characteristics of disease \\
Severity \\
Chronic or acute \\
Patient related \\
Patients own view of required therapy \\
Cognitive functioning \\
Health literacy \\
Motivation for self-care \\
Social support \\
Therapy related \\
Multiple medications \\
Complexity of therapy \\
Adverse drug reactions \\
Duration of therapy \\
\hline
\end{tabular}

increases with the number of chronic diseases and drugs. The management of chronic diseases required a continuous psychological adaptation and behavioral reorganization that may lead to significant changes with respect to therapeutic indications. ${ }^{5}$ On the other hand, polypharmacy is associated with inappropriate prescriptions, drug-drug and drug-disease interactions, prescription cascade all increasing the risk of adverse drug reactions that eventually lead to discontinuation of treatment. ${ }^{5}$

This work, prepared in the context of a collaborative work of A1 Action Group on Prescription and Adherence to Medical Plans of the European Innovation Partnership on Active and Healthy Ageing, aims to 1) review of the most frequent interventions employed to improve medication adherence as well as the measured outcomes and improvements achieved; 2) review some particularities associated with aging and with cognitive impairment or dementia; and 3) evaluate the main limitations of the available studies on adherence.

\section{Behavioral interventions}

Behavioral interventions aim to change individual behavior in those aspects related to everyday life; in case of adherence, they aim to modify patients' behavior toward treatment. ${ }^{19}$ Interventions are characterized by cognitive-behavioral techniques and therapies focused on dysfunctional emotions, behaviors and cognitions with the aim to promote healthy lifestyles, and positive changes toward symptoms and treatment. ${ }^{20}$

Behavioral interventions for enhancing medication adherence have shown contradictory results. ${ }^{20-23}$ The most effective interventions are those that integrate multiple components, with the limitations of being not cost-effective and not easily implemented in everyday clinical practice. ${ }^{23}$ By this reason, there is a growing interest in the development of effective behavior interventions, particularly for elderly people, in which behavioral counseling is directly offered to patients by health care professionals specifically trained in cognitive behavioral methods, independently of their profession; counseling and behavioral aspects are integrated and combined in more articulated interventions. Telephone follow-up and home visits, particularly in associations with educational components, seem to have a positive impact, providing planning and support, and integrated pre and post discharge interventions. ${ }^{24-26}$

Medication management programs involving pharmacists, such as MeMO and DelpHi studies, provided interesting results in decreasing nonadherence and discontinuation in chronic therapy. ${ }^{27-29}$ As a secondary outcome, structured counseling sessions and continuous monitoring of drug use improved 
patient's satisfaction and medication knowledge; furthermore, since intervention was tailored on nonadherence and high-risk patients, cost-effectiveness was favorable, overcoming one of the main limitation of many previous studies. ${ }^{28}$

A recent paper showed a short-term efficacy of a single consultation-based session of 30 minutes, performed by a trained nurse, on enhancing objectively assessed adherence to oral medication lowering glucose serum levels in older patients. ${ }^{30}$ This intervention includes a motivational component, in which the nurse elicited patients' beliefs relevant to their intention to take medication regularly as prescribed using a series of questions based on the theory of planned behavior. In a second interventional component, the nurse asked patients to generate and write down the exact circumstances in which they would take their medication. Even if no long-term data are available and, therefore, persistence could not be assessed, the necessity of adopting reliable outcome measures and of simplifying the intervention is interestingly targeted in this trial. Furthermore, feasibility and reproducibility are also taken into account since authors considered them essential to evaluate the implementation, in clinical practice, of interventions for behavior change. ${ }^{31}$

Randomized controlled trials with wider samples are required to assess the effectiveness of psychosocial, behavioral, and self-management interventions. Nevertheless, it must be taken into account that studies should focus on simple methods to improve adherence in order to increase the feasibility of their implementation in clinical practice, which is the real challenge for the future.

\section{Educational interventions}

Patient education has recently become an important domain of medicine. Patient education has been used, as widely shown in the literature, to enforce medication adherence. ${ }^{32-38}$

Health care providers can educate patients to promote medication adherence by adequately explaining how to take a medicine, by raising and discussing with patients any reluctance to take medicines, and by discussing with patients their beliefs and knowledge about their health and associated treatments. ${ }^{39}$

Communication and information about pharmacological treatment and diseases are critical, and the opinion that interventions to improve adherence must be focused not only on patients but also on broader context and health care system is being progressively accepted. In order to achieve better adherence, it is important to provide information to the patient about their disease and treatment falls, in the need of adopting patient-centered care, and sharing decision-making principles.
Many systematic reviews have examined patient education interventions in patient-centered health care system to improve medication adherence. Some of them include specific disease interventions, while others focus on only one type of intervention that is applied to different diseases. ${ }^{40}$

Viswanathan et $\mathrm{al}^{41}$ review interventions that are associated with improvements on adherence to crosswise multiple clinical conditions, including reduction in copayments or improving drug coverage, case management, and educational programs. The results showed that the same intervention could have different clinical benefits across diseases, particularly for hypertension where in both case management and face-to-face education by pharmacists were associated with an enhanced adherence. Integrated interventions including education, case management, and behavioral support showed to increase adherence for many chronic diseases, even if follow-up data on long-term adherence was not available. ${ }^{41}$

Little or no differences in the degree of nonadherence or in other clinical outcomes were found in most reviews that examine education or information alone. In some studies, the knowledge is improved by patient's education programs, but no improvements were found in the degree of nonadherence. ${ }^{42,43}$ Education or information interventions to increase adherence to medicines post organ transplantation has been associated with an improved knowledge, ${ }^{44}$ but inconsistently adherence. However, by combining patient information and behavioral interventions, an improvement in adherence and in target immunosuppressant blood levels was achieved. Education and/or counseling delivered by pharmacists shows similarly mixed results for adherence and other clinical outcomes. ${ }^{45,46}$ However, certainly raised knowledge may increase adherence, particularly when patients are aware of the consequences of irregular therapy or its cessation. ${ }^{47}$

Generally, an intervention with a single component (information or education) seems to be ineffective to improve adherence or other clinical outcomes, but there is some evidence that they may improve knowledge. However, when associated with other interventions, namely, self-management skills training, counseling, or as part of pharmacist-delivered packages of care, there is some evidence that education or information has a positive impact in adherence and in other clinical outcomes and knowledge, but results are not consistent.

\section{Integrated care interventions}

Integrated care (also often referred as disease management or care management) has been defined in various studies as a group of techniques and organizational models to 
enhance connectivity, alignment, and collaboration within and between health care providers at different levels (funding, administrative, and/or provider) ${ }^{48}$ Among the most frequently encountered items in integrated care programs, we highlight the following: multidisciplinary of the health care providers team; multidisciplinary clinical pathways and feedback, reminders, and health care professional education; and self-management support and patient education, associated with structured clinical follow-up and case management. ${ }^{49}$

Integrated care interventions aim to increase quality of care and of life and intensify health care satisfaction and efficiency for providers and patients with complex health problems. ${ }^{50,51}$ Despite its benefits, using integrated care has proved to be a daunting task. Due to the complexity of each health care system, providers of health care sometimes may find it difficult to coordinate their work and actions in creating integrated care plans for patients. However, highquality care requires collaboration and coordination among professionals. ${ }^{52}$ The main stakeholders who usually sit at the same table to discuss adherence programs for patients are the general practitioners, the pharmacists, and the health insurers. Insurers started showing greater interest in disease management plans, as they understood that methods to reduce dispersion and to attain enhanced results could be achieved at plausible costs. ${ }^{53}$ Various studies have shown that integrated care plans provided by interdisciplinary teams can reduce the risk of hospitalization and the length of stay in hospital or in nursing home. ${ }^{54}$ Furthermore, the close collaboration between team members can be important to the success of a given intervention and may determine the effectiveness of any care plan of this sort. ${ }^{55}$

Literature review showed that in different clinical studies on various disease groups, integrated care programs seems to have positive impact on patient care quality. A metaanalysis identified a set of six elements for the good rollout of a disease management program: community resources and policies, health care organization, self-management support, delivery system design, decision support, and clinical information systems. ${ }^{56}$

All studies have shown that integrated care interventions affect positively the health care quality. However, disease management programs differ in range, type, and components. Furthermore, no clear definition has been adopted. It is important to recognize these differences, in order not to take incorrect conclusions on the effectiveness of these programs.

\section{Self-management interventions}

The increasing prevalence of chronic diseases poses some new questions to the policymakers and health care providers, as they have to decide how to invest the available resources to manage these patients. ${ }^{57}$ Wilkinson and Whitehead ${ }^{58}$ define self-management as:

the ability of the individual, in conjugation with family, community, and health professionals, to manage symptoms, treatments, lifestyle changes, and psychosocial, cultural, and spiritual consequences of chronic disease.

The self-management incorporates multiple concepts, such as self-care, self-monitoring, adherence, health behavior change, patient education, and collaborative care, which intend to inform the patients about their own disease, so that they have a more active role in its treatment. ${ }^{57}$ Moreover, there are a lot of care domains that are under direct control from the patients, ${ }^{60}$ including lifestyle choices, access to their own records, self-monitoring, and adherence to medication. The use of technological devices in self-management interventions is increasing when compared with face-to-face meetings. Technology-based self-management includes telephone support/counseling alone, telemedicine/telehealth/ home telecare/telemonitoring, web-based interventions/ interactive computerized health communication and cell phones/text messaging.

Self-management interventions, generally, comprise several components, such as provision of information, medication, problem-solving, and support. Sustainability is an important issue on self-management interventions, as the maintaining long-term benefits is important to change behavior. Problem-solving and coping skills were found to be important factors influencing long-term maintenance of behavior change. ${ }^{61,62}$

Several systematic reviews and meta-analysis showed the effectiveness of self-management programs/interventions. Patients with chronic conditions showed evidence of improvements in $\mathrm{HbA}_{1 \mathrm{c}}$ levels, systolic and diastolic blood pressure, and pain associated with self-management interventions. ${ }^{63}$ Increasing patient's knowledge and providing them with basic skills to manage their disease can results in health benefits and could reduce their dependence on health care services use and associated costs. ${ }^{64-66}$ No evidence was found that tailored self-management interventions for type 2 diabetes, hypertension, and heart diseases had impact on selfmanagement activities. ${ }^{65}$ Nevertheless, tailored interventions modestly improved specific self-management behaviors of dietary fat intake, physical activity level, and screening behaviors. Empowerment-based self-management interventions on chronic metabolic diseases patients presented higher and longer effects than the traditional education or self-management interventions without empowerment-based 
interventions. ${ }^{67}$ The use of mobile phones and short messages service showed a strong evidence that their use improve adherence to appointments and medication, self-management of asthma, hypertension and diabetes, and short-term smoking cessation. ${ }^{68}$

Self-management interventions, which include patient education, reminders, and financial incentives, have benefits for patients with chronic diseases, namely, in terms of knowledge, self-efficacy, and health status. Nevertheless, the cost-effectiveness of self-management interventions is difficult to evaluate due to the variety of methods used.

\section{Risk communication interventions}

Risk perception is a core dimension of intentional nonadherence to medications. ${ }^{69}$ It is defined as the perceived probability, likelihood, or susceptibility to harm and is a salient construct in many explanatory theories of health behavior. ${ }^{70}$ In the literature on adherence, patients' engagement with a behavior, in this case, medication taking, is influenced by the person's appraisal of risk associated with the behavior and the consequent harmful or protective outcomes. Effective risk communication by health care professionals is therefore central to ensure information about risks and benefits being communicated accurately to enable patients to take informed decisions. Risk perception is a complex construct, multidimensional in nature, which must be considered from both a cognitive and affective perspective. ${ }^{69}$ Due to its complexity, patient and clinician perceptions of risk are often contradictory. ${ }^{70}$ Given the significance of this construct on the potential modification of medication adherent behavior, strategies to enhance risk communication are the key. ${ }^{71}$

Patient decision aids are relatively new educational tools that have been developed to facilitate patient-clinician presentation of risk information and shared decision-making. ${ }^{72}$ The aids contain evidence-based information about the health condition, treatment options, and potential benefits and harms. Decision aids can be done by using pamphlets, videos, or web-based tools. ${ }^{73}$ Kunzt et al $^{74}$ conducted a robust qualitative review of patient-centered interventions to improve patient medication management and adherence. These interventions engaged the patient in prescribing decisions by communicating why a medication was indicated, its risks and benefits, and the likely impact on the patient's health. Six studies employed decision aids as the principal component of their interventions, ${ }^{75-79}$ and three studies reported that patients' understanding of risk was improved and decisional conflict lessened. ${ }^{77-79}$ However, alterations in risk perception did not automatically translate into positive changes to adherent behavior. ${ }^{74}$ Stacey et $\mathrm{al}^{73}$ carried out a Cochrane review to evaluate the effects of decision aids for people facing treatment or screening decisions. The review included 115 studies involving 34,444 participants. Of the 115 studies, 25 (21.7\%) described the effect of including risk information in decision aids on the accuracy of patients' perceived probabilities of outcomes. Nineteen of the 25 studies noted that patients who received a decision aid intervention were more likely to have accurate risk perceptions, when compared with those who did not receive this information (relative risk of 1.82 [95\% confidence interval: $1.52-2.16]){ }^{73}$ In terms of the impact of decision aids on behavior, specifically medication-taking behavior, the findings were mixed. Decision aids are associated with an increase in the number of individuals choosing medication for cardiovascular disease prevention, and mixed results were evident for the uptake of antithrombosis therapy and diabetes medications. No differences were found between groups for choices about hypertension therapy, breast cancer chemotherapy, schizophrenia medication, immunotherapy for multiple sclerosis, flu vaccine, osteoporosis treatment, chemotherapy for advanced cancer, chemopreventive medications, and antibiotics for upper respiratory tract infections. $^{73}$

The evidence for the efficacy of risk communication through the medium of decision aids in promoting adherent behavior is unclear. This ambiguity mirrors the conclusions made in numerous systematic reviews ${ }^{23,80-82}$ in relation to the effectiveness of the majority of adherence enhancing interventions. Nieuwlaat et $\mathrm{al}^{22}$ showed that across the body of evidence, effects were inconsistent from study-to-study, and only a minority of lowest risk of bias RCTs improved both adherence and clinical outcomes.

The reviewers suggested that the studies at lowest risk of bias generally are associated with complex interventions with multiple components, trying to overcome barriers to adherence by means of tailored ongoing support via intense education, counseling or daily treatment support by professionals in addition to support from family or peers. The communication of risk information through decision aids has demonstrated potential in altering perceptions and to a lesser extent adherent behavior. This adherence enhancing strategy should not be relied upon as a sole moderator of adherent behavior, but rather as a strategy that is integrated within a complex intervention. Furthermore, it would be prudent to investigate further the pragmatics and optimum methods of presenting and conveying risk information given its multidimensional nature. 


\section{Packaging and daily reminders}

Adherence is a problem for $50 \%-60 \%$ of all people affected by chronic illnesses. ${ }^{84}$ Patient reminders help people to improve their health in order to remind them to take their medicine or to schedule medical visits and screenings. ${ }^{85}$ There are different kinds of reminders such as reminder phone calls, text messages, pagers, interactive voice response (IVR) systems, video telephone calls, medication boxes, or personalized blisters. ${ }^{13}$ Studies have shown that often enough patients are not adherent to their medication, as they should and some of them forget to refill or take their medication. Various studies have been carried out in order to test different tools aimed at improving adherence to medication. A pilot study investigated whether an IVR can help to increase medication adherence. This automated IVR system calls the patients and reminds them to take their medicine or refill their prescriptions after they have communicated their information about their demographic, telephone, and medication to an IVR system. According to the study, the system did not succeed to improve medication adherence mainly due to technical problems patients had (incorrect time of calls and so on). ${ }^{87}$

The First Myocardial Infarction Risk Reduction Program showed that reminders such as reminder postcards and telephone calls about risk reduction for patients who have a high risk of a heart attack do not have any effect on medication adherence. ${ }^{88}$

Another study focused on the comparison of different medication reminders used on two groups of patients with type 2 diabetes. The first group's adherence was supported with active care management such as home telemonitoring, and the second received a monthly care coordination telephone call. Both groups got monthly calls for diabetes education and self-management review. The glycemia control increased in both groups and also improved the blood level of the first group. ${ }^{89}$

A study in which a nurse calls patients suffering from high blood pressure twice a month for 2 years to promote medication adherence and to monitor health behaviors showed that medication adherence increased by $9 \%$ compared to a group without any support. This system is easy to implement, and the study examines that a system like this has competency to be expanded. ${ }^{90}$

Another study of telephone-based interventions investigated the benefit of monthly phone calls after the diagnosis of osteoporosis in comparison to the usual care by a primary care physician. The aim of the study was a filled prescription for a 3-month supply of medication in 130 days. The study showed that patients who received the monthly reminder call improved their adherence to the treatment. During this study, an organization-wide program that encouraged the use of osteoporosis medication was also started, and the authors believed that this initiative could have helped for the positive results of the study. ${ }^{91}$

The biggest part to assure optimal treatment of asthma and preventing exacerbation are self-management skills. A study was performed to show the effects of self-management education on adherence over a long time. The methods included self-monitoring, individualized action plans, and information about assessment and correct use of an inhaler. The results showed that such an intervention increases medication adherence and provides clinical data of asthma control. ${ }^{92}$

Another study about medication adherence of people who suffer from asthma exanimated that if patients receive a SMS that reminds them to take their medication the adherence increases compared to the group of patients who did not. ${ }^{93}$ One SMS per day was enough to increase the medication adherence of patients who suffer from asthma.

There was no difference found concerning the right use of medication between patients receiving new antidepressant prescriptions who were part of a telephone-based care management program and to those who were not. A study surveyed whether a care management program has any benefits for medication adherence compared to a usual treatment without any support. ${ }^{94}$

A literature review reported about studies that examined how health care can benefit from the use of mobile phones. Different clinical studies on different groups such as HIV-infected patients, other chronic diseases patients, and healthy patients were conducted are as follows: four studies on HIV-infected patients; eight studies on patients suffering from other chronic diseases; and one study on healthy individuals showed increasing of adherence. The medication reminder in all studies was sending an SMS. Due to the variety of studies, the results showed mixed outcomes of the benefits of medication reminder systems. Overall, studies disclosed $65 \%$ positive outcomes in terms of improved adherence. ${ }^{84}$

Reminder packaging is another way to stop the decrease in medication adherence. A study showed that patients who used reminder packaging were more adherent and had a lower refill time than patients without reminder packaging. ${ }^{95}$

A review that deals with different researches about reminder packaging shows new analysis of 12 trials. The 
result was that medication packaging not only influenced adherence but also clinical outcomes. Poor quality or no significant outcomes were the two reasons why some of the studies had little results. Content of the studies were various, from over the counter medication to different prescription drugs and types of packaging, the patients were suffering of different illnesses. Prefilled medication boxes or foil-backed blisters were the most used tools to improve the adherence. Some studies focused on specific patients for example, in one study, a special focus was laid on patients with low literacy skills, and the patients received pictures that show which pill they have to take as well as date and point of time. ${ }^{96}$

Another review came to the same conclusion: the use of reminder packaging had positive effect on adherence as well as on clinical outcomes. The review deals with different studies, in all of the investigated trials at least one medication had to be taken without any assistance to see if there is a difference between people using reminder packaging and those who are not. The result of the studies was that in 17 studies reminder packaging had an effect on at least one adherence parameter. There was also clear research gaps reported..$^{97}$

Another study aimed at analyzing how medication packaging helps older patients. Two groups of elderly people who have high blood pressure were compared, one was asked to use a daily dose blister packaging (Pill Calendar), and the other one used usual bottles of loose tablets. It turned out that patients with the Pill Calendar had a higher adherence, refilled their prescriptions more often, and it had a positive effect on their clinical outcome. ${ }^{98}$

All studies have showed that reminder in any variation and reminder packaging have a positive impact on medication adherence and often also on clinical results. Further research is needed in order to reduce information gaps and to lower the risk that a falsification of data occurs.

\section{Clinical trials in elderly people}

Some problems related to medications in the elderly have been studied and published in observational cohort studies. ${ }^{99-104}$ Results from these studies show some significant data, for example:

- Elderly people have a double risk of developing adverse effects than younger people.

- $20 \%$ of older people in Europe receive at least one inappropriate drug.

- $30 \%$ of hospital admissions among elderly people are caused by adverse effects of drugs.
- It has been estimated that in 1994, in the USA alone, over 100,000 people died due to an adverse reaction to a drug.

Moreover, commonly prescribed drugs and some of the most frequently self-administered drugs are causing hospitalizations and deaths. Therefore, detection and prevention of adverse reactions are very important in elderly because:

- Frequency is seven times greater.

- There are $16 \%$ of hospitalization and $50 \%$ of deaths related to medication.

- Aging increases the number of drugs taken, and therefore, the possibility to develop an adverse reaction.

- Between $50 \%$ and $70 \%$ of the adverse reactions observed are preventable.

Taking into account that adherence depends in part on the behavior of the patients, we need to decrease the adverse reactions in the patients and increase the drug effectiveness to establish the risk benefit of them. Only in case that we have a good risk benefit rate and evidence to demonstrate it, we will be able to treat patients with guarantee.

Until recently, elderly people, particularly frail and very old people, have been excluded from some randomized controlled trials without justification. Yet, the randomized controlled trials are widely acknowledged as the "gold standard" experimental design in clinical medicine and, given the disproportionate burden of disease and use of health and social care resources by older people, it would seem especially important that they should be included in clinical trials in significant numbers. The inclusion of older people in clinical trials will be able to establish the benefit risk rate in this population, as this rate is quite different from other young adults.

Underrepresentation of older people in clinical trials in the past is evident from systematic reviews in a wide range of age-related conditions, including heart failure, hypertension, coronary heart disease, arthritis, dementia, Parkinson's disease, urinary incontinence, and cancer. Furthermore, the minority of older people who were included were often robust, being free of the comorbidities, and concurrent treatments that are characteristic of old age. Thus, even available data on older people are biased. Consequently the evidencebased management is often inadequate, leading to uncertainty about advantages and disadvantages of treatments. This in turn results in delays in implementation of potentially valuable interventions in the population who are often at greatest absolute risk and so stand to gain the greatest potential benefit from treatment. Probably, the most important reason to exclude older people from the randomized controlled trials is related to the excessive paternalism of younger researchers 
and relatives, ignoring autonomy right of the older people to make own decisions. ${ }^{104-106}$

The European research consortium PREDICT (Increasing the PaRticipation of the ElDerly In Clinical Trials) has compiled a charter for the rights of elderly people in clinical trials. ${ }^{107}$ Given the accumulating evidence of past neglect, it is important that future randomized controlled trials reflect the patient populations that will receive treatments in future clinical practice.

Therefore, to improve adherence is absolutely necessary to know certainly the treatment in this population is effective but the risk is not higher.

\section{Cognitive impairment or dementia associated with nonadherence}

Cognitive impairment is a frequent comorbidity, particularly in the elderly, and a challenge for health care professionals, for optimizing care and management. Adherence to complex medication regimens and treatment of multiple medical problems is an everyday issue when dealing with the cognitively impaired. Understanding their strategies for maintaining regular use of even complex drug regimens is still limited, and in patients with dementia no evidence-based recommendations are available. ${ }^{108}$

Often, an overlap between intentional and unintentional nonadherence may be encompassed in older adults, especially when fragile or isolated, ${ }^{109}$ and it is well known that caregivers may do the difference. ${ }^{110,111}$ The caregiver role is essential in supporting adherence, by integrating and compensating the decreasing abilities of the partner even when switching patient medication self-management to the responsibility of other person is unclear. Furthermore memory, executive functions, and global cognitive functioning may be compromised in the caregiver as well.

A systematic evidence-based review showed the importance of relational aspects in improving adherence; patients with dementia benefit more from frequent human communication as reminder systems than nonhuman reminders, ${ }^{112}$ once again emphasizing the necessity to sustain the elderly with communication and relationships in their difficult trip through life more than the instrumental aid of information and communication technologies alone.

Recently, integrated interventions are proposed for compensating patients' and families' frailties due to dementia: regular medication reviews and systematic cooperation between physicians and pharmacists was implemented in the DelpHi-approach providing first interesting results for a comprehensive approach, where adherence is only a part of a wider outcome model of integrated care. ${ }^{26}$

More studies are required in order to take into account the interactions among the individual patient's cognitive status and his/her particular living situation. In a wider perspective provided by the ICF WHO disability model, adherence of the elderly cognitive impaired patient should be seen as the outcome of personal aspects modulated by environmental barriers and facilitators. ${ }^{113}$

\section{Conclusion}

The aim of this review was to reemphasize the important role of medication adherence in the management of chronic diseases, particularly in old persons. While facing a clinical situation in which targets are not reached, despite substantial efforts to prescribe the most adequate therapy, nonadherence should be considered. Medication adherence remains a challenge for health care professional and scientists, as their efforts to improve and explain patients' adherence appear to be ineffective; poor adherence is associated with high health care costs, lower quality of life, and poor health outcomes. Motivating patients to follow medical treatment is part of the history of medicine.

A lot of interventions to improve adherence to medical plans have been described in literature, despite some isolated success, most interventions failed in their aims. ${ }^{114-117}$ As previously reported, there is evidence that improving medication adherence differs by clinical condition. The chronic diseases most studied in terms of interventions to improve adherence are hypertension, depression, dyslipidemia, asthma, and diabetes. ${ }^{8,9,12,15,115-117}$ Of these, most interventions that were associated with adherence improvement did not lead to improvements in health outcomes, such as quality of life, patient's satisfaction, biomarkers, morbidity, mortality, health care utilization quality of care, and costs.

In fact, adherence rates improvement is smaller than expected. One of the reasons for the slow progress seems to be the lack of comprehensive theoretical models to explain nonadherence and to lead to a potentially successful intervention. ${ }^{18,119}$ Interventions that are supported by behavior models and theories were described to be more successful than those based on intuition. Indeed, different models and theories have been adapted from various disciplines and have been used to design health interventions, such as the theory of planned behavior, the transtheoretical model, and the health belief model. ${ }^{118-120}$ Moreover, along this revision, we identified inconsistent methodology and findings across the studies, different approaches for the same tool. Finally, 
most of the tools were complex, labor-intensive, and not predictably effective. Most of the studies are mainly focused on short-term adherence, and no consistent results were presented for long-term evidence, and the current methods of improving adherence for chronic illness are mostly complex and not very effective.

It will be important in future research to evaluate the efficacy of intervention tools on long-term effect (medication persistence) and the role of formal and informal caregivers in the support on patient's adherence, to improve health literacy as an integrating/transversal tool across all intervention approaches, and to find new and innovative single-intervention strategies to improve adherence and methods to monitoring adherence. Finally, it is of paramount importance for the establishment of innovative studies focusing on implementation of research studies in clinical practice, where integrated care needs to be associated with cost-effective interventions.

\section{Disclosure}

The authors report no conflicts of interest in this work.

\section{References}

1. Dunbar J. Adherence to medical advice: a review. Int J Mental Health. 1980;9:70-87.

2. Roberson MH. The meaning of compliance: patient perspective. Qual Health Res. 1992;2:7-26.

3. Sabate E, editor. Adherence to Long-Term Therapies: Evidence for Action. Geneva: World Health Organization; 2003.

4. Cutler DM, Everett W. Thinking outside the pillbox-medication adherence as a priority for health care reform. $N$ Engl J Med. 2010;362: 1553-1555.

5. Majani G. Compliance, Adesione, Aderenza. I Punti Critici Della Relazione Terapeutica. Milano: McGraw-Hill; 2001.

6. Korsch BM, Gozzi EK, Francis V. Gaps in doctor-patient communication. 1: doctor-patient interaction and patients' satisfaction. Pediatrics. 1968;42:855-871.

7. Davis MS. Variations in patients' compliance with doctors' advice: an empirical analysis of patterns of communication. Am J Public Health. 1968;58:274-288.

8. Morris LS, Schulz RM. Patient non-compliance - an overview. J Clin Pharm Ther. 1992;17:283-295.

9. Donavan JL. Patient decision making. The missing ingredient in compliance research. Int J Technol Assess Health Care. 1995;11: 443-455.

10. Lassen LC. Patient compliance in general practice. Scand J Prim Health Care. 1989;7:179-180.

11. Einarson TR. Drug-related hospital admission. Ann Pharmacother. 1993; 27:832-840.

12. Dulmen S, Sluijs E, Dijk L, Ridder D, Heerdink R, Bensing J. Patient adherence to medical treatment: a review of reviews. BMC Health Serv Res. 2007;7:55.

13. Fenerty SD, West C, Davis SA, Kaplan SG, Feldman SR. The effect of reminder system on patients' adherence to treatment. Patient Prefer Adherence. 2012;6:127-135.

14. Wroth TH, Pathman DE. Primary medication adherence in a rural population: the role of the patient-physician relashionship and satisfaction with care. J Am Board Fam Med. 2006;19:478-486.
15. Sokol MC, McGuigan KA, Verbrugge RR, Epstein RS. Impact of medication adherence on hospitalization risk and health care cost. Med Care. 2005;165:1749-1755.

16. Amado L, Ferreira N, Miranda V, et al. Santos-Silva A, Costa E. Selfreported medication adherence in patients with end-stage kidney disease under online-hemodiafiltration. J Renal Care. In press 2015.

17. Goldney RD, Fisher LJ. Use of prescribed medications in a South Australian communitysample. Med J Aust. 2005;183:251-253.

18. Elliott RA. Problems with medication use in the elderly: an Australian perspective. J Pharm Pract Res. 2006;36:58-66.

19. NICE Public Health Guidelines. Behaviour Change at Population, Community and Individual Levels. London: NICE Public Health Guidelines; 2007.

20. Clarkesmith DE, Pattison HM, Lane DA. Educational and behavioural interventions for anticoagulant therapy in patients with atrial fibrillation. Cochrane Database Syst Rev. 2013;6:CD008600.

21. George J, Elliott RA, Stewart DC. A systematic review of interventions to improve education taking in elderly patients prescribed multiple medications. Drugs Aging. 2008;25:307-324.

22. Nieuwlaat R, Wilczynski N, Navarro T, et al. Interventions for enhancing medication adherence. Cochrane Database Syst Rev. 2014;11: CD000011.

23. Haynes RB, Ackloo E, Sahota N, McDonald HP, Yao X. Interventions for enhancing medication adherence. Cochrane Database Syst Rev. 2008; (2):CD000011.

24. Garcia-Caballos M, Ramos-Diaz F, Jimenez-Moleon JJ, Bueno-Cavanillas A. Drug-related problems in older people after hospital discharge and interventions to reduce them. Age Ageing. 2010;39(4): 430-438.

25. Mistiaen P, Poot E. Telephone follow-up, initiated by a hospitalbased health professional, for postdischarge problems in patients discharged from hospital to home. Cochrane Database Syst Rev. 2006;4: CD004510.

26. Mistiaen P, Francke AL, Poot E. Interventions aimed at reducing problems in adult patients discharged from hospital to home: a systematic meta-review. BMC Health Serv Res. 2007;7:47.

27. Stuurman-Bieze AG, Hiddink EG, van Boven JF, Vegter S. Proactive pharmaceutical care interventions decrease patients' nonadherence to osteoporosis medication. Osteoporos Int. 2014;25(6):1807-1812.

28. van Boven JF, Stuurman-Bieze AG, Hiddink EG, Postma MJ, Vegter S. Medication monitoring and optimization: a targeted pharmacist program for effective and cost-effective improvement of chronic therapy adherence. J Manag Care Pharm. 2014;20(8):786-792.

29. Fiß T, Thyrian JR, Wucherer D, et al. Medication management for people with dementia in primary care: description of implementation in the DelpHi study. BMC Geriatr. 2013;13:121.

30. Farmer A, Hardeman W, Hughes D, et al. An explanatory randomised controlled trial of a nurse-led, consultation-based intervention to support patients with adherence to taking glucose lowering medication for type 2 diabetes. BMC Fam Pract. 2012;13:30.

31. Hardeman W, Lamming L, Kellar I, et al. Implementation of a nurse-led behaviour change intervention to support medication taking in type 2 diabetes: beyond hypothesised active ingredients (SAMS Consultation Study). Implement Sci. 2014;9:70.

32. Holman H. Chronic disease - the need for a new clinical education. JAMA. 2004;292(9):1057-1059.

33. Van Wijk BL, Klungel OH, Heerdink ER, de Boer A. Effectiveness of interventions by community pharmacists to improve patient adherence to chronic medication: a systematic review. Ann Pharmacother. 2005;39(2): 319-328.

34. Stevenson FA, Cox K, Britten N, Dundar Y. A systematic review of the research on communication between patients and health care professionals about medicines: the consequences for concordance. Health Expect. 2004;7(3):235-245.

35. Gleeson T, Iversen MD, Avorn J, et al. Interventions to improve adherence and persistence with osteoporosis medications: a systematic literature review. Osteoporosis Int. 2009;20(12):2127-2134. 
36. Schedlbauer A, Davies P, Fahey T. Interventions to improve adherence to lipid lowering medication. Cochrane Database Syst Rev. 2010;3: CD004371.

37. Schroeder K, Fahey T, Ebrahim S. Interventions for improving adherence to treatment in patients with high blood pressure in ambulatory settings. Cochrane Database Syst Rev. 2004;(2):CD004804.

38. Vergouwen AC, Bakker A, Katon WJ, Verheij TJ, Koerselman F. Improving adherence to antidepressants: a systematic review of interventions. J Clin Psychiatry. 2003;64(12):1415-1420.

39. Ratanawongsa N, Karter A, Parker MM, et al. Communication and medication adherence: the diabetes study of Northern California. JAMA Intern Med. 2013;173(3):210-218.

40. Mahtani KR, Heneghan CJ, Glasziou PP, Perera R. Reminder packaging for improving adherence to self-administered long-term medications. Cochrane Database Syst Rev. 2011;9:CD005025.

41. Viswanathan M, Golin CE, Jones CD, et al. Interventions to improve adherence to self-administered medications for chronic diseases in the United States: a systematic review. Ann Intern Med. 2012;157: 785-795.

42. Al-Aqeel S, Al-Sabhan J. Strategies for improving adherence to antiepileptic drug treatment in patients with epilepsy. Cochrane Database Syst Rev. 2011;1:CD008312.

43. Mbuba CK, Ngugi AK, Newton CR, Carter JA. The epilepsy treatment gap in developing countries: a systematic review of the magnitude, causes, and intervention strategies. Epilepsia. 2008;49(9):1491-1503.

44. De Bleser L, Matteson M, Dobbels F, Russell C, De Geest S. Interventions to improve medication-adherence after transplantation: a systematic review. Transpl Int. 2009;22(8):780-797.

45. van Wyk JT, van Wijk MA, Moorman PW, Mosseveld M, van der Lei J. User requirements rating and knowledge-level of general practitioners at the start of CholGate - a lipid management decision support project. AMIA Annu Symp Proc. 2005;2005:1146.

46. Koshman SL, Charrois TL, Simpson SH, McAlister FA, Tsuyuki RT. Pharmacist care of patients with heart failure. Arch Intern Med. 2008;168(7): 687-694.

47. Olszanecka-Glinianowicz M, Chudek J. The level of health education in the Polish population. Ann Agric Environ Med. 2013;20:559-565.

48. Kodner D. Integrated Long Term Care Systems in the New MilleniumFact or Fiction? San Francisco, CA: American Society on Aging Summer Series on Aging; 1999.

49. Ouwens M, Wollersheim H, Hermens R, Huscher M, Grol R. Integrated care programmes for chronically ill patients: a review of systematic reviews. Int J Qual Health Care. 2005;17(2):141-146.

50. Davies B. The reform of community and long term care of elderly persons an international perspective. In: Scharf T, Wenger GC, editors. International Perspectives on Community Care for Older People. Aldershot: Avebury; 1995.

51. Leutz W. Five laws for integrating medical and social services: lessons from the United States and the United Kingdom. Milbank Q. 1999;77(1): 77-110.

52. Glouberman S, Mintzberg H. Managing the care of health and the cure of disease - part 1: differentiation. Health Care Manage Rev. 2001;26(1): 56-69.

53. Kesteloot K. Disease management. A new technology in need of critical assessment. Int J Technol Assess Health Care. 1999;15(3): 506-519.

54. Bernabei R. Randomized trial of impact of model of integrated care and case management for older people living in the community. BMJ. 1998; 316:1348-1351.

55. Bula C, Alessi C, Aronow H, Yuhas K, Gold M, Nisenbaum R. Community physicians cooperation with a program of in-home comprehensive geriatric assessment. J Am Geriatr Soc. 1995;43(9):1016-1020.

56. Bodenheimer T, Wagner EH, Grumbach K. Improving primary care for patients with chronic illness: the chronic care model, Part 2. JAMA. 2002; 288(15):1909-1914.

57. Richard AA, Shea K. Delineation of self-care and associated concepts. J Nurs Scholarsh. 2011;43(3):255-264.
58. Wilkinson A, Whitehead L. Evolution of the concept of self-care and implications for nurse: a literature review. Int J Nurs Stud. 2009;46: 1143-1147.

59. Richard AA, Shea K. Delineation of self-care and associated concepts. J Nurs Scholarsh. 2011;43:255-264.

60. Logan AG. Transforming hypertension management using mobile health technology for telemonitoring and self-care support. Can J Cardiol. 2013; 29:579-585

61. Newman S, Steed L, Mulligan K. Chronic Physical Illness: Self-Management and Behavioral Interventions. Berkshire: Open University Press; 2009

62. World Health Organization (WHO). Preparing a health care workforce for the 21st century: the challenge of chronic conditions. WHO Report. Geneva: WHO; 2005

63. Chodosh J, Morton SC, Mojica W, et al. Meta-analysis: chronic disease self-management programs for older adults. Ann Intern Med. 2005; $143: 427-438$

64. Coster S, Norman I. Cochrane reviews of educational and self-management interventions to guide nursing practice: a review. Int J Nurs Stud. 2009;46:508-528.

65. Radhakrishnan K. The efficacy of tailored interventions for selfmanagement outcomes of type 2 diabetes, hypertension, or heart disease: a systematic review. J Adv Nurs. 2012;68(3):496-510.

66. Panagioti M, Richardson G, Small N, et al. Self-management support interventions to reduce health care utilization without compromising outcomes: a systematic review and meta-analysis. BMC Health Serv Res. 2014;14:356

67. Kuo C, Lin C, Tsai F. Effectiveness of empowerment-based selfmanagement interventions on patients with chronic metabolic diseases: a systematic review and meta-analysis. Woldviews Evid Based Nurs. 2014; 11:301-315

68. Jones KR, Lekhak N, Kaewluang N. Using mobile phones and short message service to deliver self-management interventions for chronic conditions: a meta-review. Worldviews Evid Based Nurs. 2014;11(2):81-88.

69. Lehane E, McCarthy G, Collender V, Deasy A, O’Sullivan K. The reasoning and regulating medication adherence instrument for patients with coronary artery disease: development and psychometric evaluation. J Nurs Meas. 2013;21(1):64-79.

70. Shreck E, Gonzalez JS, Cohen HW, Walker EA. Risk perception and self-management in urban, diverse adults with type 2 diabetes: the improving diabetes outcomes study. Int J Behav Med. 2014;21(1): 88-98.

71. Walker EA, Mertz CK, Kalten MR, Flynn J. Risk perception for developing diabetes: comparative risk judgments of physicians. Diabetes Care. 2003;26:2543-2548.

72. Stalmeier PF. Adherence and decision AIDS: a model and narrative review. Med Decis Making. 2011;31(1):121-129.

73. Stacey D, Légaré F, Col NF, et al. Decision aids for people facing health treatment or screening decisions. Cochrane Database Syst Rev. 2014;1:CD001431.

74. Kuntz JL, Safford MM, Singh JA, et al. Patient-centered interventions to improve medication management and adherence: a qualitative review of research findings. Patient Educ Couns. 2014;97:310-326.

75. Fagerlin A, Zikmund-Fisher BJ, Nair V, et al. Women's decisions regarding tamoxifen for breast cancer prevention: responses to a tailored decision aid. Breast Cancer Res Treat. 2010;119:613-620.

76. Kasper J, Kopke S, Muhlhauser I, Nubling M, Heesen C. Informed shared decision making about immunotherapy for patients with multiple sclerosis (ISDIMS): a randomized controlled trial. Eur J Neurol. 2008; 15:1345-1352.

77. Mann DM, Ponieman D, Montori VM, Arciniega J, McGinn T. The statin choice decision aid in primary care: a randomized trial. Pat Educ Couns. 2010;80:138-140.

78. Montori VM, Shah ND, Pencille LJ, et al. Use of a decision aid to improve treatment decisions in osteoporosis: the osteoporosis choice randomized trial. Am J Med. 2011;124:549-556. 
79. Thomson RG, Eccles MP, Steen IN, et al. A patient decision aid to support shared decision-making on anti-thrombotic treatment of patients with atrial fibrillation: randomised controlled trial. Qual Saf Health Care. 2007;16:216-223.

80. Nieuwlaat R, Wilczynski N, Navarro T, et al. Interventions for enhancing medication adherence. Cochrane Database Syst Rev. 2014;11: CD000011.

81. Krass I, Schieback P, Dhippayom T. Adherence to diabetes medication: a systematic review. Diabet Med. 2015;32(6):725-737.

82. Chong WW, Aslani P, Chen TF. Effectiveness of interventions to improve antidepressant medication adherence: a systematic review. Int J Clin Pract. 2011;65(9):954-975.

83. Haynes RB, Ackloo E, Sahota N, McDonald HP, Yao X. Interventions for enhancing medication adherence. Cochrane Database Syst Rev. 2008;(2):CD000011.

84. Anglada-Martinez H, Riu-Viladoms G, Martin-Conde M, RoviraIllamola M, Sotoca-Momblona JM, Codina-Jane C. Does mHealth increase adherence to medication? Results of a systematic review. Int J Clin Pract. 2015;69(1):9-32.

85. Agency for Healthcare Research and Quality. 2014. Available from: http://healthit.ahrq.gov/ahrq-funded-projects/patient-reminders-andnotifications

86. Fenerty SD, West C, Davis SA, Kaplan SG, Feldman SR. The effect of reminder systems on patients adherence to treatment. Patient Prefer Adherence. 2012;6:127-135.

87. Reidel K, Tamblyn R, Patel V, Huang A. Pilot study of an interactive voice response system to improve medication refill compliance. $B M C$ Med Inform Decis Mak. 2008;8:46.

88. Guthrie RM. The effects of postal and telephone reminders on compliance with pravastian therapy in a national registry: results of the first myocardial infarction risk reduction program. Clin Ther. 2001;23(6):970-980.

89. Stone RA, Rao RH, Sevick MA, et al. Active care management supported by home telemonitoring in veteran with type 2 diabetes: the DiaTel randomized controlled trial. Diabetes Care. 2010;33(3):478-484.

90. Bosworth HB, Olsen MK, Neary A, et al. Take control of your blood pressure (TCYB) study: a multifactorial tailored behavioral and educational intervention for achieving blood pressure control. Patient Educ Couns. 2008;70(3):338-347.

91. Waalen J, Bruning AL, Peters MJ, Blau EM. A telephone-based intervention for increasing the use of osteoporosis medication: a randomized controlled trial. Am J Manag Care. 2009;15(8):e60-e70.

92. Janson SL, McGrath KW, Covington JK, Cheng SC, Boushey HA. Individualized asthma self-management improves medication adherence and markers of asthma control. J Allergy Clin Immunol. 2009;123(4):840-846.

93. Strandbygaard U, Thomsen SF, Backer V. A daily SMS reminder increases adherence to asthma treatment: a three month follow-up study. Respir Med. 2010;104(2):166-171.

94. Simon GE, Ludman EJ, Operskalski BH. Randomized trial of a telephone care management program for outpatients starting antidepressant treatment. Psychiatr Serv. 2006;57(10):1441-1445.

95. Dupclay L, Eaddy M, Jackson J, Raju A, Shim A. Real-world impact of reminder packaging on antihypertensive treatment adherence and persistence. Patient Prefer Adherence. 2012;6:499-507.

96. Kennedy L. Reminder Packaging Helps Patients Take Medication as Directed; 2011. Available from: http://mylocalhealthguide. com/2011/09/14/reminder-packaging-helps-patients-take-medicationsas-directed

97. Boeni F, Spinatsch E, Suter K, Hersberger KE, Arnet I. Effect of drug reminder packaging on medication adherence: a systematic review revealing research gaps. Syst Rev. 2014;24:29.

98. Schneider PJ, Murphy JE, Pedersen CA. Impact of medication packaging on adherence and treatment outcomes in older ambulatory patients $J$ Am Pharm Assoc (2003). 2008;48(1):58-63

99. Huybrechts KF, Gerhard T, Crystal S, et al. Differential risk of death in older residents in nursing homes prescribed specific antipsychotic drugs: population based cohort study. BMJ. 2012;344:e977.
100. Rossom RC, Rector TS, Lederle FA, Dysken MW. Are all commonly prescribed antipsychotics associated with greater mortality in elderly male veterans with dementia? J Am Geriatr Soc. 2010;58(6):1027-1034.

101. Liperoti R, Onder G, Landi F, et al. All-cause mortality associated with atypical and conventional antipsychotics among nursing home residents with dementia: a retrospective cohort study. J Clin Psychiatry. 2009;70(10):1340-1347.

102. Fischer MA, Jones JB, Wright E, et al. A randomized telephone intervention trial to reduce primary medication nonadherence. J Manag Care Spec Pharm. 2015;21(2):124-131.

103. Hwang DK, Liu CJ, Pu CY, Chou YJ, Chou P. Persistence of topical glaucoma medication: a nationwide population-based cohort study in Taiwan. JAMA Ophthalmol. 2014;132(12):1446-1452.

104. Chong E, Wang H, King-Shier KM, Quan H, Rabi DM, Khan NA. Prescribing patterns and adherence to medication among South-Asian, Chinese and white people with type 2 diabetes mellitus: a population-based cohort study. Diabet Med. 2014;31(12):1586-1593.

105. Cunico C, Picheth G, Correr CJ, Scartezini M. Assessing the adherence to and the therapeutic effectiveness of hypolipidemic agents in a population of patients in Brazil: a retrospective cohort study. Pharm Pract (Granada). 2014;12(2):378.

106. Bayer A, Laosa O. Los ancianos en los ensayos clínicos. Tratado de Medicina Geriatrica. 2014:73-80.

107. PREDICT. Increasing the Participation of the Elderly in Clinical Trials. Literature Review 2008. Available from: www.predicteu.org/ Reports/PREDICT_WP1_Report.pdf. Accessed May 15, 2012.

108. Arlt S, Lindner R, Rösler A, von Renteln-Kruse W. Adherence to medication in patients with dementia: predictors and strategies for improvement. Drugs Aging. 2008;25:1033-1047.

109. Mukhtar O, Weinman J, Jackson SH. Intentional non-adherence to medications by older adults. Drugs Aging. 2014;31:149-157.

110. Trivedi RB, Bryson CL, Udris E, Au DH. The influence of informal caregivers on adherence in COPD patients. Ann Behav Med. 2012;44(1): 66-72.

111. Xiong T, Li J, Mao J, Xu J. Medication-related problems among community-dwelling older adults after recent hospital discharge in mainland China. Nurs Res. 2014;63:439-445.

112. Campbell NL, Boustani MA, Skopelja EN, Gao S, Unverzagt FW, Murray MD. Medication adherence in older adults with cognitive impairment: a systematic evidence-based review. Am J Geriatr Pharmacother. 2012;10:165-177.

113. World Health Organization. ICF-International Classification of Functioning, Disability and Health. Geneva: WHO Library; 2001.

114. Cochrane MG, Bala MV, Downs KE, Mauskopf J, Ben Joseph RH. Inhaled corticosteroids for asthma therapy: patient compliance, devices, and inhalation technique. Chest. 2000;117:542-550.

115. Haddad M, Inch C, Glazier RH, Wilkins AL, Bayoumi A, Rourke S. Patient support and education for promoting adherence to highly active antiretroviral therapy for HIV/AIDS. Cochrane Database Syst Rev. 2000:1-10.

116. Hampson SE, Skinner TC, Hart J, et al. Effects of educational and psychosocial interventions for adolescents with diabetes mellitus: a systematic review. Health Technol Assess. 2001;5:1-79.

117. Lorig K, Holmann H. Arthritis self-management studies: a twelve year review. Health Educ. 1993;20:17-28.

118. Sirur R, Richardson J, Wishart L, Hanna S. The role of theory in increasing adherence to prescribed practice. Physiother Can. 2009;61: 68-77.

119. Carpenter CJ. A meta-analysis of the effectiveness of health belief model variables in predicting behavior. Health Commun. 2010;25: 661-669.

120. Jones CJ, Smith H, Llewellyn C. Evaluating the effectiveness of health belief model interventions in improving adherence: a systematic review. Health Psychol. 2014;8:253-269. 
Patient Preference and Adherence

Dovepress

\section{Publish your work in this journal}

Patient Preference and Adherence is an international, peer-reviewed, open access journal that focuses on the growing importance of patient preference and adherence throughout the therapeutic continuum. Patient satisfaction, acceptability, quality of life, compliance, persistence and their role in developing new therapeutic modalities and compounds to optimize

clinical outcomes for existing disease states are major areas of interest for the journal. This journal has been accepted for indexing on PubMed Central. The manuscript management system is completely online and includes a very quick and fair peer-review system, which is all easy to use. Visit http://www. dovepress.com/testimonials.php to read real quotes from published authors.

Submit your manuscript here: http://www.dovepress.com/patient-preference-and-adherence-journal 